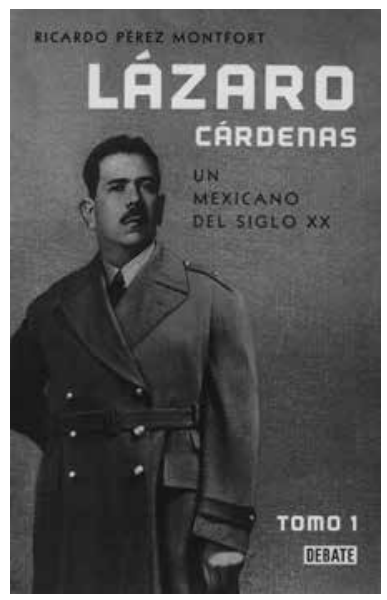

Lázaro Cárdenas and His Century

Anna Ribera Carbó Instituto Nacional de Antropología e Historia, Dirección de Estudios Históricos,

Ciudad de México, México annariberacarbo@gmail.com

Desacatos 59 , enero-abril 2019, pp. 202-206
- Lázaro Cárdenas. Un mexicano

del siglo $x x$, tomo 1

RICARDo PÉrEZ MONTFORT, 2017

Debate-Penguin Random House, México

\section{El siglo de Lázaro Cárdenas}

\author{
ANNA RIBERA CARBÓ
}

ázaro Cárdenas. Un mexicano del siglo XX es la culminación de muchas de las preocupaciones y afanes historiográficos de Ricardo Pérez Montfort. En sus páginas encontramos reflexiones, largamente elaboradas, en torno a la historia política, la historia social, la historia cultural — con énfasis en la cultura popular y la creación de estereotipos nacionales o locales—, el análisis de imágenes fotográficas o cinematográficas, los versos y canciones populares. Quienes hayan seguido la trayectoria del autor podrán leer, entre líneas, el andamiaje preparado durante años de estudio para construir este trabajo.

Este primer tomo abarca la biografía de Lázaro Cárdenas desde su nacimiento hasta los momentos previos a su campaña electoral y ascenso a la presidencia de México. Pero hay mucho más que eso. Es una historia política en cuanto se inmiscuye de manera irremediable en los tejemanejes políticos del complejo escenario de la Revolución y el periodo posterior. Pérez Montfort reconstruye con detalle los vínculos establecidos por Lázaro Cárdenas a lo largo de su vida. La trayectoria de quien llegaría a la presidencia de México con sólo 39 años de edad se explica, en gran medida, a partir de sus relaciones personales, políticas y militares, establecidas desde su infancia y juventud provincianas, y después en su incorporación a la Revolución. Su carrera militar, en 
la que sería la facción triunfante; el constitucionalismo del Noroeste; su tránsito por las regiones del Occidente, desde su natal Michoacán hasta Sonora y de regreso, y luego en otras geografías, como el Istmo de Tehuantepec y la Huasteca veracruzana, fue clave en el tejido de una red sin la cual no podría explicarse su rápido ascenso en las filas del ejército de la Revolución.

De estas relaciones, hay tres que me gustaría comentar por su relevancia. La que sostuvo con Plutarco Elías Calles, su jefe militar, mentor político y ejemplo revolucionario, resulta indispensable para comprender la permanencia y ascenso de Cárdenas durante sus 20 años de formación, su presencia en momentos y lugares clave de la lucha armada y la construcción del Estado posrevolucionario. Si los años de la Revolución fueron complicados, los de las grillas políticas en los años siguientes lo fueron más aún. Marcada por la presencia de dos figuras tan fuertes como Obregón y Calles, aliados y rivales, incluso después del asesinato del primero, la década de 1920 se caracterizó por las intrigas de salón y de cuartel que definieron los ascensos o caídas en desgracia de muchos actores de la época. Fueron años de reacomodos en el interior de la "familia revolucionaria", encabezada por el poder omnímodo de Calles, con episodios que remiten a la novela Los relámpagos de agosto, de Jorge Ibargüengoitia, de la que transcribo un fragmento:

—Este Partido Único no me gusta nada.

- A mí tampoco - dijo Trenza-. Pero es demasiado grande para ir en contra de él — en esto tenía mucha razón.

Entonces se nos presentó la solución del problema con gran claridad: si hay una aplanadora, más vale estar encima que debajo de ella.

-Lo único que nos queda, Lupe —me dijo Germán, que estaba pensando lo mismo que yo-, es apoderarnos del famoso Partido Único (1984: 54).
La ácida pluma de Ibargüengoitia retrata los enredos en los que estaban metidos políticos y militares al empezar la década de 1930: cómo apoderarse del partido controlado por Calles. Pascual Ortiz Rubio, Manuel Pérez Treviño, Emilio Portes Gil, Gonzalo N. Santos, Joaquín Amaro, Abelardo L. Rodríguez, entre otros, participan en el "estira y afloja" de la política mexicana, en la que Lázaro Cárdenas ocuparía puestos tan relevantes como la Secretaría de Gobernación, la presidencia del Partido Nacional Revolucionario (PNR) y la Secretaría de Guerra y Marina, sin estar interesado en llegar a la primera magistratura o al menos sin parecerlo. Eso sí, mantuvo su estrecha relación con Calles, al margen de la construcción de sus propias bases políticas, sobre todo desde su gubernatura en Michoacán, ensayo general de lo que haría en la presidencia.

La relación con Francisco J. Múgica también fue esencial en la vida de Lázaro Cárdenas. Su brillante trayectoria revolucionaria tuvo su momento culminante en el Congreso Constituyente de 1917, en el que ocupó la presidencia de la Primera Comisión de Puntos Constitucionales. Era gobernador de Michoacán cuando conoció a Cárdenas, de 25 años de edad, y se desempeñaba como jefe de Operaciones en el estado. El gobierno de Múgica terminó confrontado con la presidencia de Obregón y Cárdenas intervino de manera discreta pero definitiva, para que el gobernador sobreviviera, literalmente, a su enfrentamiento con el presidente. Su amistad y complicidad política se consolidarían después, en 1925, cuando coincidieron en la Huasteca veracruzana. Múgica estaba ahí como representante de un bufete de abogados para resolver litigios de empresas petroleras. Cárdenas llegó como jefe de la zona militar. Pasaron tres años juntos en una región petrolera marcada por la presencia de compañías extranjeras. Fue una experiencia que terminó de convencerlos de que las soluciones a los problemas económicos y sociales del país debían pasar por la recuperación de los recursos de la nación, y de que 
la manera de hacerlo estaba asentada en el artículo 27 de la Constitución.

La amistad con Múgica, 11 años mayor, perduraría en los tiempos por venir. Mantuvieron una intensa relación epistolar mientras Múgica estuvo a cargo del penal de las Islas Marías, y por supuesto, durante la presidencia de Cárdenas. El alejamiento ideológico respecto de Calles tiene mucho que ver con el acercamiento a Múgica. Pérez Montfort analiza esta relación excepcional de dos políticos que compartieron su visión del país, que reconocieron los talentos del otro y las debilidades propias, y que constituyeron lo que he llamado un tándem revolucionario, inédito en nuestra historia. La biografia de uno es inexplicable sin la del otro.

La tercera relación, que apenas asoma en este volumen, es con Manuel Ávila Camacho. Rescatar la colaboración que comenzó en 1921, cuando el poblano se incorporó al Estado Mayor de Cárdenas, quien se encontraba en el Istmo de Tehuantepec para intentar pacificar al rebelde Cástulo Pérez, es de suma importancia. Ávila Camacho estaría bajo las órdenes de Cárdenas de ahí en adelante. Seguir esta vinculación en el terreno militar ayudará a comprender mejor el relevo electoral de 1940, en apariencia incomprensible, que sin duda aparecerá en el tomo 2.

Este libro es también una historia militar. Desde la incorporación a las fuerzas del general Guillermo García Aragón, en julio de 1913, del entonces joven tenedor de libros y empleado de una imprenta, hasta su designación como secretario de Guerra y Marina a principios de 1933, transcurrieron 20 años de una rápida, pero cautelosa y pensada carrera militar. El libro recrea las fracturas, divisiones, deslealtades y traiciones que caracterizaron al ejército revolucionario en esas dos décadas, para convertirse, a partir de los Tratados de Teoloyucan, en el nuevo ejército nacional. Nos adentra en la manera en que Cárdenas transitó por ellas, siempre leal a su jefe Plutarco Elías Calles, vinculado desde el principio al grupo que saldría triunfante de la marejada revolucionaria.

Las numerosas investigaciones sobre Lázaro Cárdenas han privilegiado el análisis de su presidencia. El acercamiento pormenorizado a su actuación como militar es uno de los aportes de esta obra, que lo sigue en las campañas de la Revolución en Sonora; en Michoacán, para combatir a los forajidos Jesús Cíntora, Fernando Altamirano y José Inés Chávez García; en la Huasteca, contra las fuerzas de Manuel Peláez, que se sumó al Plan de Agua Prieta contra Venustiano Carranza; en la pacificación del Istmo de Tehuantepec, cuando fue derrotado por los delahuertistas en 1923, y al enfrentar a los cristeros en el Occidente. Pérez Montfort explica de manera convincente algunos temas delicados, como el asesinato de Carranza en Tlaxcalantongo, a manos de Rodolfo Herrero, subalterno de Cárdenas, caso explotado por los detractores del michoacano.

Pérez Montfort cuenta que en 1921, tal vez por el recrudecimiento de la campaña del yaqui, que contravenía su postura personal sobre la solución del tema de los pueblos indios de México, Cárdenas tuvo la intención de retirarse un momento del ejército. No fue la única ocasión. En 1932 le escribió a Francisco J. Múgica, entonces director del penal de Islas Marías, acerca de su intención de dejar el ejército y las funciones públicas al terminar su gestión al frente del estado, para dedicarse al desempeño de labores de carácter social en la Confederación Revolucionaria Michoacana del Trabajo. Múgica respondió:

Me refiero a su propósito de permanecer un año, después de dejar el Gobierno, al lado de la Confederación, pues dado nuestro medio intranquilo, ambicioso y suspicaz no concibo siquiera que ejercitando funciones militares pudiera dedicarse a la labor social que urgentemente necesita desarrollarse en el estado [...], tampoco concibo cómo al salir de la política no reanude automáticamente sus funciones en el ejército del pueblo. 
Le voy a decir por qué: cada día que pasa me confirma más en la idea de que el mando es una necesidad ingente en nuestro medio político y social, sin esta condición nadie vale nada en México así sean claros los antecedentes y halagadoras las circunstancias, pero la verdad brutal, tajante, incontrovertible es que sin el mando todo valimiento vale pelos - y perdóneme la frase tan vulgar en esta carta tan seria-.

Si usted tiene pues, que de hecho sé que lo tiene, empeño en salvaguardar los ideales de la Revolución y de conservar por lo menos algunas de las organizaciones que han logrado crearse, llenas de dificultades y restricciones, conserve usted el mando militar (carta de Múgica a Cárdenas, Isla María Madre, 27 de abril de 1932, citado en Ribera, 1999: 121).

Continuaba: "es indispensable que quienes representan impulso sano estén en funciones, para que llegado el momento puedan afrontar una situación y si no edificarla por lo menos influenciarla en el sentido del patriotismo y de la Revolución" (citado en Ribera, 1999: 121).

El 1 de enero de 1933, Cárdenas fue nombrado secretario de Guerra y Marina por el presidente Abelardo L. Rodríguez. Queda claro en esta obra que comentamos que la trayectoria política de Lázaro Cárdenas no se explica sin su hábil carrera militar y su convencida pertenencia al ejército. Amalia Solórzano contaba que una de las cosas que le gustaba al general, de la casa que construyeron en las Lomas de Chapultepec, en un terreno que ella recibió como regalo de Ávila Camacho, era que desde ahí se podía ver la Secretaría de la Defensa Nacional.

Este libro es también una historia social que reconstruye la vida en varias regiones del país por las que transitó Lázaro Cárdenas a lo largo de sus primeras cuatro décadas. Las actividades económicas, las estructuras de la sociedad, los conflictos de clase, las formas de vida cotidiana no son sólo un escenario, sino parte clave en el análisis de las razones detrás de la movilización popular que dio sustento al proceso revolucionario y que explican las trayectorias de sus actores. Pérez Montfort cita una anécdota, que ubica en las orillas del lago de Pátzcuaro y que yo he encontrado situada en un viaje en ferrocarril de Mazatlán a Guadalajara, en 1942, narrada por Abel Camacho Guerrero, quien fuera secretario de Múgica. Cárdenas habría comentado al entonces gobernador del territorio sur de la Baja California que en muchas ocasiones se había preguntado qué hubiera sido de ellos sin la Revolución, a lo que Múgica habría contestado: "usted, tejedor de rebozos, y yo, profesor de escuela rural" (citado en Ribera, 1999: 13). La anécdota es reveladora de la conciencia que ambos tenían de que sus vidas estaban marcadas por el proceso de transformación social que fue la Revolución mexicana.

Otro tema que vale la pena comentar es la definición ideológica de Cárdenas. Como muchos otros políticos de la época, se adscribió a un socialismo mexicano que, a mi parecer, está más cerca de una lectura radical de la Constitución de 1917. Creo que muchos de quienes fueron postulados por partidos de denominación socialista estaban más próximos a lo que se conocería como "nacionalismo revolucionario”. Aunque el propio Múgica afirmaría, en la entrevista que le hicieron Sylvia y Nathaniel Wey, que "fundamentalmente no hay ninguna diferencia entre la filosofía del señor Cárdenas y la tradición socialista de Europa" (citado en Ribera, 1999: 151), nunca fueron más allá de los límites que estableció el código de Querétaro: reparto agrario, legislación laboral, educación laica y comprometida socialmente, anticlericalismo, preocupación por los pueblos indios. Al respecto, Adolfo Gilly sostiene que "no eran aquellos socialismos marxistas ni eran su fuerte la teoría o la organización de los trabajadores. Los militares mexicanos [...] se sumergirían en las condiciones de su tiempo, pero su territorio no eran los libros ni las fábricas, sino las armas" (1994: 401). 
Aunque sus políticas no carecían de radicalismo y su discurso adoptó mucho de la retórica socialista en boga ante la enorme presencia de la Revolución bolchevique, no estoy muy segura de que ellos lo fueran. No sé si alguien que considera que "el resurgimiento de México sólo puede ser producto de una justa y mejor distribución de la propiedad” (p. 398), como declaró Cárdenas a la prensa al ser nombrado presidente del PNR, es socialista. El mismo Plan Sexenal no fue más allá de lo propuesto en la asamblea constituyente. En todo caso, es un tema interesante sobre el que habrá que reflexionar.

Sólo quisiera apuntar un par de aspectos más. Uno se refiere al puritanismo de algunos sectores revolucionarios, reflejado en campañas antialcohólicas, en su aversión a los juegos de azar y las corridas de toros. Alguna vez consideré interesante investigar el tema, aunque no he encontrado el tiempo para hacerlo, y me gustó encontrarlo aquí, salpicado en las páginas del libro. El puritanismo no fue exclusivo de nuestra Revolución, pero tuvo exponentes destacados. ${ }^{1}$ El otro es lo que pasaba en el mundo. Salvo en algunos episodios referidos a las crisis diplomáticas en la relación con Estados Unidos, este libro se concentra en los acontecimientos mexicanos. Estoy segura de que el tomo 2 dedicará amplias reflexiones a lo que ocurría fuera de nuestra geografía, si consideramos que el autor ha escrito trabajos fundamentales, como Hispanismo y falange (Pérez Montfort, 1992), y que la gestión presidencial de Lázaro Cárdenas participó de manera activa en lo que acontecía en el mundo convulso de la década de 1930.

A semejanza de los trabajos ya clásicos de John Womack (1969), sobre Emiliano Zapata, y Friedrich Katz (1998), sobre Pancho Villa, la biografía que Pérez Montfort ha escrito de Lázaro Cárdenas, a partir de una vastísima bibliografía, un alud de artículos y una rica investigación de archivo, contribuye en definitiva a recuperar esta figura imprescindible, que no es sólo "un mexicano del siglo Xx", como se asienta en el título, sino uno de los personajes esenciales para comprender los 100 años que siguieron a la Revolución. Espero ya el segundo tomo. D

1 Sobre estos temas, véase Pérez Montfort (2016).

\section{Bibliografía}

Gilly, Adolfo, 1994, El cardenismo, una utopía mexicana, Cal y Arena, México.

Ibargüengoitia, Jorge, 1984, Los relámpagos de agosto, Joaquín Mortiz (Serie del volador), México.

Katz, Friedrich, 1998, Pancho Villa, Era, México.

Pérez Montfort, Ricardo, 1992, Hispanismo y falange. Los sueños imperiales de la derecha española y México, Fondo de Cultura Económica, México.

—_, 2016, Tolerancia y prohibición. Aproximaciones a la historia social y cultural de las drogas en México 1840-1940, Debate, México. Ribera Carbó, Anna, 1999, La patria ha podido ser flor. Francisco J. Múgica, una biografía política, Instituto Nacional de Antropología e Historia, México.

Womack Jr., John, 1969, Zapata y la Revolución mexicana, Siglo XXI Editores, México. 